\title{
Thymoma presenting as a middle mediastinal mass
}

\author{
R. BRADFORD* \\ B.Sc., F.R.C.S.
}

J. MCLLELLAND

B.Sc., M.B., B.S.

\author{
S. L. COHEN \\ F.R.C.P.
}

P. GOLDSTRAW
F.R.C.S.

Departments of Thoracic Surgery and Medicine, University College Hospital, Gower Street, London WC1E 6AU

\section{Summary}

A case of a middle mediastinal mass which proved to be a thymoma is presented. The diagnostic difficulties that middle mediastinal masses produce and the investigations used to delineate them are discussed.

KEY WORDS: thymoma, middle mediastinum, diagnosis.

\section{Introduction}

We report a case in which a middle mediastinal mass, presumed to be a pleuropericardial cyst, had been noted on a chest X-ray 11 years before it rapidly enlarged. It subsequently proved to be a thymoma.

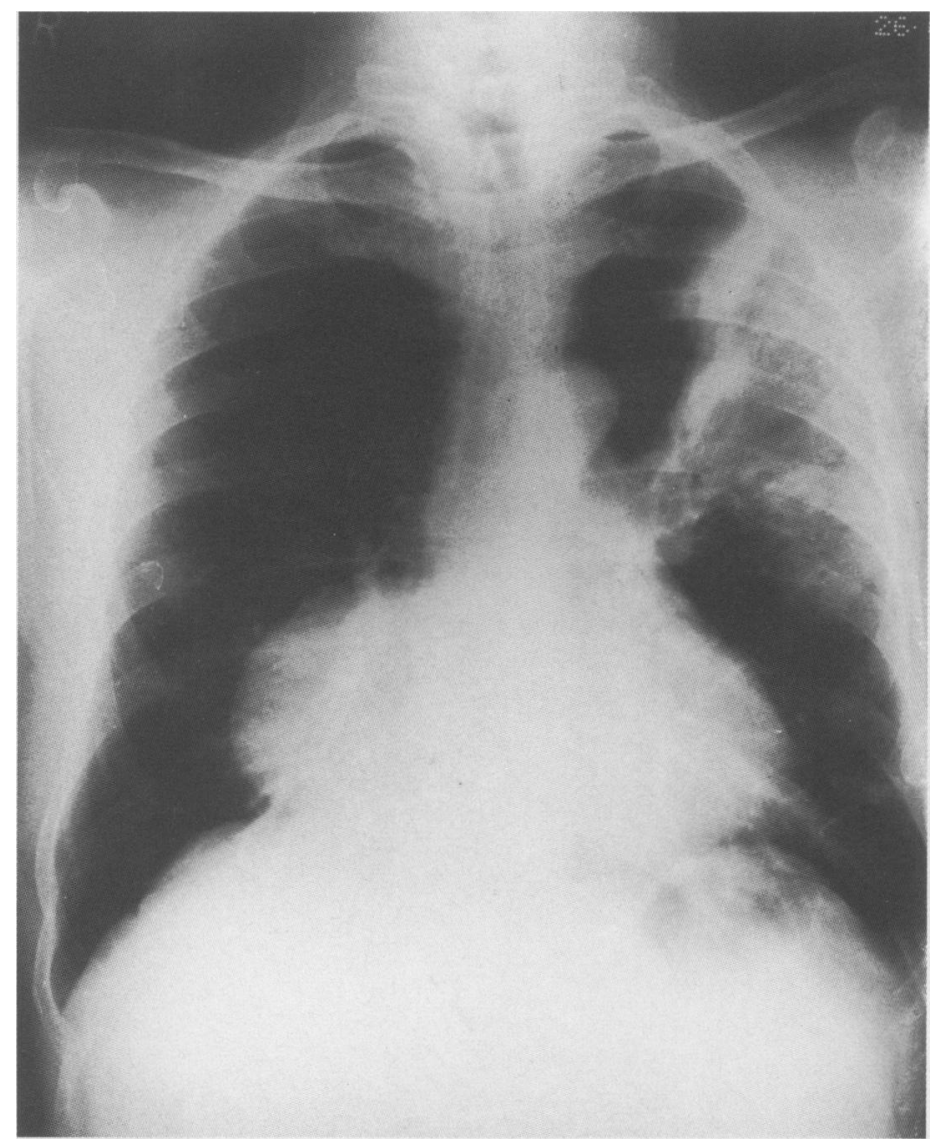

FIG. 1. Chest $\mathrm{X}$-ray showing mass at right cardiophrenic angle and left upper lobe consolidation.

*Present address: Maida Vale Hospital, London W9 1TL. 


\section{Case report}

A 61-year-old male smoker had been seen at another hospital in 1970 with pleurisy. The chest radiogram showed a mass at the right cardiophrenic angle, confirmed on tomography. It was concluded that the mass was a pleuropericardial cyst. Eleven years later he presented with the symptoms and signs of a left upper lobe pneumonia which responded rapidly to antibiotic treatment. The chest X-ray confirmed the left upper lobe consolidation and revealed a mass at the right cardiophrenic angle (Fig. 1). In the light of the previous history this was assumed to be a pleuropericardial cyst. Six months later the patient returned complaining of a nonproductive cough and increasing shortness of breath. His chest X-ray showed that there had been a rapid increase in the size of the mass which was now displacing the mediastinum to the left (Fig. 2). His vital capacity was $2 \cdot 12$ litres compared with as predicted value of 3.46 litres. An echocardiogram was. reported as normal.

Open biopsy of the mass revealed it to be a spindle cell thymoma. At right thoracotomy a $30 \times 25 \mathrm{cmp}$ encapsulated solid mass was located in the media stinum, adherent to the pericardium and the righ middle lobe. The blood supply of the tumoun originated from the anterior mediastinum. The tumour was excised together with the middle lobe. If was necessary to divide four ribs to deliver the tumour. After a short period of assisted ventilation the patient made a complete recovery.

\section{Discussion}

The middle mediastinum contains the pericar: dium, the heart and the large vessels entering of leaving the latter. A mass in the middle mediastinum

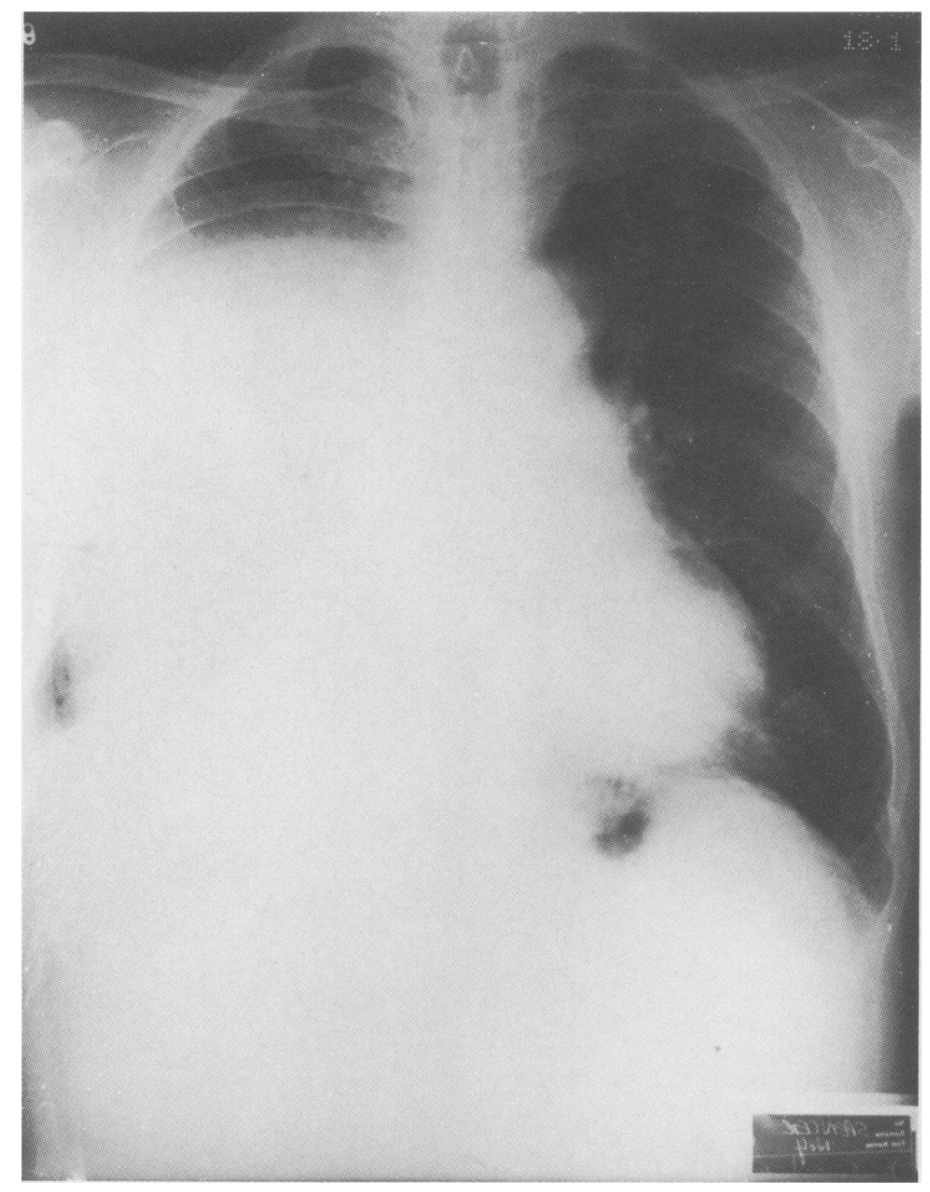

FIG. 2. Chest X-ray 6 months later showing increase in the size of the mediastinal mass. 
may arise from any one of these structures. Thymoma is the commonest anterior mediastinal tumour (Shields, 1972; Benjamin et al., 1972; Adenbanojo and Nicola, 1976) but they have been previously reported in the middle mediastinum (Adenbanojo $e t$ al., 1977), where they may lead to diagnostic difficulties.

Opacities within the anterior costodiaphragmatic sulcus present particular diagnostic difficulty as it is here that the anterior and the middle compartments of the mediastinum converge with the diaphragm. A barium meal and follow-through should be undertaken to exclude herniation through the foramen of Morgagni. Thereafter echocardiography (Schloss et al., 1975) and ultrasonography (Friday, 1973) may be useful in differentiating between solid and cystic lesions. Computerized axial tomography may be of value in delineating the anatomical relationship of the mass and may also suggest a cystic lesion. There are, however, reports of misleading densities on computerized axial tomography of the mediastinum (Marvasti et al., 1981). Only if such cystic lesions yield the typical 'spring-water' fluid of the pleuropericardial cyst would we feel justified in making this diagnosis and treating the condition expectantly (Emerson, 1981). Unless these stringent conditions are satisfied histological diagnosis is mandatory.

\section{Acknowledgments}

We would like to thank Mr D. Ellis for preparing the photographs and Miss Y. Bisset for typing the manuscript.

\section{References}

adenbanojo, S.A., Grillo, I.A., Falase, A.O. \& Aghadiuno, P.U. (1977) Middle mediastinal thymoma simulating pericardial cyst. International Surgery, 62, 343.

AdEnBanojo, S.A. \& Nicola, M.L. (1976) Teratoid tumours of the mediastinum. American Surgeon, 42, 123.

BENJAMIN, S.P., MCCoRMACK, L.F., EFFLER, D.B. \& GRAVES, L.K. (1972) Primary tumours of the mediastinum. Chest, 62, 297.

EMERSON, P. (1981) Thoracic Medicine, p. 390. Butterworth, London. FrIDAY, R.O. (1973) Paracardiac cysts: diagnosis by ultrasound and puncture. Journal of the American Medical Association, 226, 82.

MAR VASTI, M.A., Mitchell, G.E., BURKe, W.A. \& MEYeR, J.A. (1981) Misleading density of mediastinal cysts on computerised tomography. Annals of Thoracic Surgery, 31, 167.

Schloss, M., Kronzon, I., Gelber, P.M., Reed, G.E. \& Berger, A. (1975) Cystic thymoma simulating constrictive pericarditis. Journal of Thoracic and Cardiovascular Surgery, 70, 143.

SHIELDS, T.W. (1972) General Thoracic Surgery, Chapter 48, p. 945. Lea and Febiger, Philadelphia.

(Accepted 14 September 1983) 